\title{
Final conclusions
}

It is necessary to establish the framework of an organization which will look after the interests of soil tillage research on an international level, e.g. by organising scientific soil tillage congresses. A preparatory committee will be set up by Prof. Dr. H. Frese, Soil Tillage Laboratory Braunschweig-Völkenrode, Germany. He has also agreed to issue occasional newsletters on current research work provided those responsible for the work send him the details. The next conference should be organized in 1964.

There are two practical aspects to the objectives of soil tillage, namely the effect on crop yields and the influence on production costs.

A theory of soil tillage in relation to crop rotations has to be formed in order to give a general explanation for the possible influence of separate tillage operations and a tillage system, in given conditions of soil type and climate.

It is advisable to recognise at least two phases in the relationship between soil tillage operations and crop growth, namely:

- the relation between soil tillage and the technological effect of the operations.

- the relation between the technological effect and plant growth.

With technological effect is meant the direct result of the operations as such;i.e. initial changes in soil structure and weed population caused by the operations.

The relationship between the yield and the soil factors determining crop growth, as well as their mutual interaction are such, that it will only occasionally be possible to indicate one single factor as the most important.

However one can aim at defining parameters which can be useful under practical conditions.

With soil factors are meant soil properties, which have a direct influence on plant growth.

With parameters are meant characterizing quantities having numerical values. They need not necessarily bear a direct relationship to plant growth.

To reach an understanding of the causative relation between soil factors and yield it would be necessary to record all the factors and the growth continuously.

Attemps should be made to list relevant parameters and to develop and improve measuring techniques to approach this ideal.

The unification of methods should be promoted by using well defined basic soil properties and where this is not practicable, by standardizing methods.

The work in this field of the Western European Working Group on Soil Structure of the International Soil Science Society should be strongly supported.

In order to promote the interchange of results of experiments carried out in different places, more attention should be paid in tillage experiments to the effective characterisation of soils, implements, operational characteristics, prevailing unusual conditions and peculiar problems.

The aforementioned working group will supply a list of recommendations for experiments in which soil structure is to be studied. 
Deep placement of organic or other substances with the aim of a long term amelioration of drought sensitive soils as discussed by EGERSzEGI merits further investigation under Western European conditions.

The same holds for minimum tillage practices discussed by BLAKE in this conference. Possibilities for establishing international series of soil tillage experiments should be examined.

The economics of soil tillage influence the kind and amount of tillage operations compatible with profitable crop yield. This aspect should be considered in soil tillage research. 